\title{
Theoretical and experimental study of the influence of temperature, humidity and density on the processes of drying, cleaning and filtration of cotton raw materials
}

\author{
Sirojiddin Fayziev*, Nafisa To'raeva, Sitora Fatullayeva \\ Bukhara Engineering Technological Institute, Bukhara, Uzbekistan \\ *E-mail: fayziyev1991@1ist.ru
}

\begin{abstract}
The article presents information about existing problems and their solutions in the process of drying cotton raw materials at cotton gin plants, patterns of changes in the humidity of cotton raw materials at different values of the warm air velocity are obtained. The influence of the density of cotton raw materials and the relative air velocity on the change in the moisture loss coefficient at different temperatures of the air flow was investigated and it was established using a laboratory device that at a density of $0.5 \mathrm{~g} / \mathrm{cm}^{3}$, the moisture loss process in cotton raw materials.
\end{abstract}

Keywords: raw cotton, material, fiber, seeds, capillary, convective, laboratory device, temperature 
УДК: 677.021 .125

\title{
Теоретическое и экспериментальное изучение влияния температуры, влажности и плотности на процессы сушки, очистки и фильтрации хлопкового сырья
}

\author{
Сирожиддин Файзиев*, Нафиса Тўраева, Ситора Фатуллаева \\ Бухарский инженерно-технологический институт, Бухара, Узбекистан. \\ *E-mail: fayziyev1991@list.ru
}

\begin{abstract}
Аннотация. В статье представлена информация о существующих проблемах и их решениях в процессе сушки хлопчатобумажного сырья на хлопкоочистительных предприятиях, получены закономерности изменения влажности хлопчатобумажного сырья при различных значениях скорости теплого воздуха. Исследовано влияние плотности хлопчатобумажного сырья и относительной скорости воздуха на изменение коэффициента влагоотдачи при различных температурах воздушного потока и установлено с помощью лабораторного прибора, что при значениях плотности $0,5 \mathrm{r} / \mathrm{cm}^{3}$ процесс влагоотдачи в хлопчатобумажном сырье выше.
\end{abstract}

Ключевые слова: хлопок-сырец, материал, волокно, семена, капилляр, конвектив, лабораторный прибор, температура

\section{1. Введение}

В мире по уровню спроса и предложения на хлопковое волокно использование энергосберегающих технологий и оборудования, применяемого при производстве этого продукта, является одним из ведущих. «По данным международного консультативного комитета (ICAC), во всем мире потреблено 24,55 млн. тонн волокна, а произведенное волокно составило 23,07 млн. тонн». Чтобы выращивать, обрабатывать, улучшать качество продукции и снижать стоимость хлопка-сырца во всем мире, необходимо внедрять высококачественные технологии, основанные на улучшении процесса сушки хлопка на хлопкоочистительных заводах. В связи с этим важно использовать методы, инструменты и устройства для повышения эффективности производства волокна и обеспечения энерго эффективности, а также устранения факторов, негативно влияющих на качество продукта [1].

В мире ведутся научно-исследовательские работы, направленные на создание новых технологий и технологий сушки хлопка-сырца, которые положительно влияют на технологические процессы первичной обработки хлопка, качество продукции. В связи с этим особое внимание уделяется созданию научной основы закономерностей изменения 
теплофизических свойств хлопка и его компонентов, обоснованию скорости построения и равномерности нестационарных процессов тепло массообмена хлопкового волокна и семян, обеспечению производства волокна с конкурентоспособными показателями качества, разработке новых технологий и техники сушки хлопка, разработке энергосберегающей машины, а также обоснованию технологического процесса, параметров и режимов работы [2].

\section{2. Методы и исследования}

Как известно, в зависимости от состояния влаги в материале и возможности ее устранения различают свободную и гигроскопичную, а также избыточную и сбалансированную влажность. Свободная влажность определяется по известной формуле [3]

$$
U_{\text {сб }}=U-U_{\Gamma}
$$

здесь, $U_{\Gamma}$ - максимальная гигроскопическая влажность материала; $U$ - общая влажность материала.

Влажный материал может выделять влагу и испарять ее в окружающую среду при определенных условиях, но он также может поглощать окружающую влагу. При сушке хлопчатобумажного сырья избыток влаги поглощается в основном за счет свободной и гигроскопичной влаги. Исследования показывают, что избыточная влажность приводит к потере качества волокна и снижению производительности машины, в то время как низкая влажность может привести к разрушению волокна и затруднению работы, поскольку скорость выхода влаги из хлопкового сырья сильно зависит от скорости воздуха. Известно, что влага, как и большинство других паров и жидких смесей, переносится из области с более высоким давлением пара (или концентрацией) в область с более низким потенциалом давления пара. Скорость передачи зависит от градиента и сопротивления тока между двумя полями [4]. Этот градиент можно увеличить, увеличив температуру и удалив застойный воздух в слое. В большинстве случаев на хлопкоочистительных предприятиях с целью повышения влажности применяют высокую скорость сушки хлопкового сырья. Но это не всегда дает положительный результат из-за высокой плотности высушиваемого хлопка [5].

Целью данного исследования являлось определение относительной скорости осушающего агента и влияния плотности хлопчатобумажного сырья на скорость потери влаги и десорбции (высыхания) при заданной температуре. Определим расход горячего воздушного потока, проходящего по его окружности, как 50-120 $\mathrm{cm}^{3} / \mathrm{c}^{-1}$, в зависимости от формы, расположенной внутри прибора. В зависимости от используемого держателя образца относительная скорость движения воздуха по трубе колебалась в пределах 0,05-0,6 м/с. На рисунке 1 показано лабораторное устройство для определения влияния плотности образца на процесс разделения влаги. Устройство состоит из двух камер: верхней и нижней, 


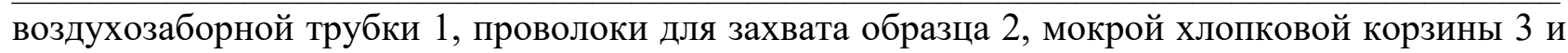
выхлопной трубы отработанного воздуха 6, противовеса 4 и игольчатого клапана 5.

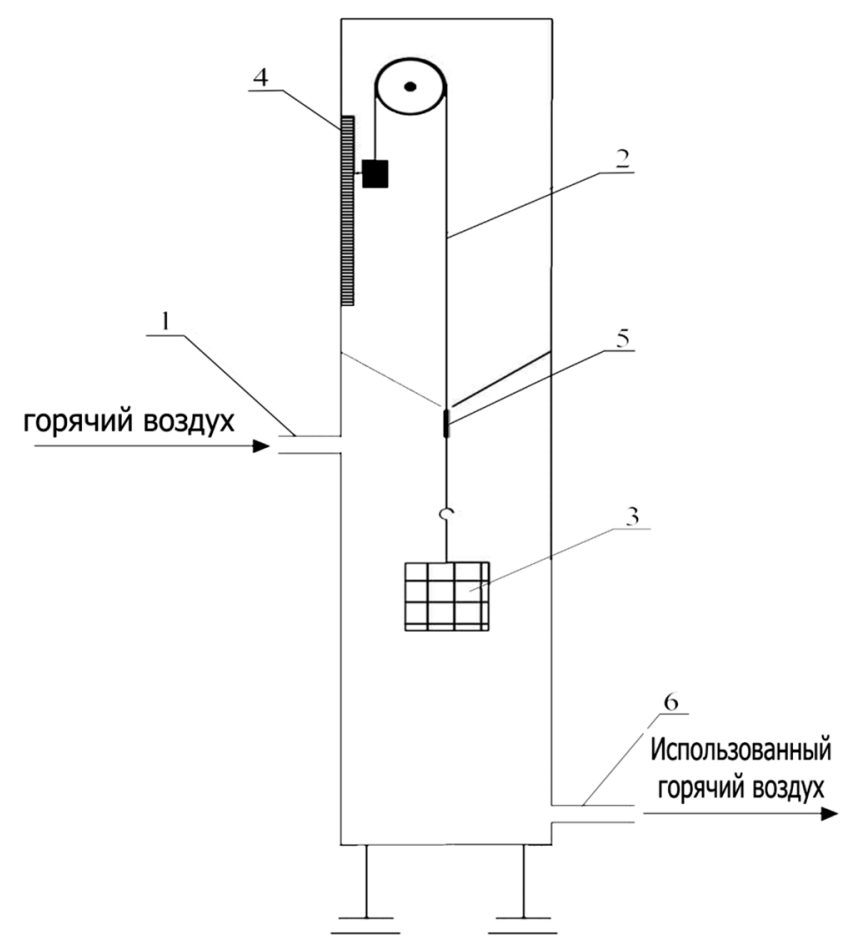

Рисунок 1. Лабораторное оборудование для определения количества выделения влаги: 1-трубка для подачи горячего воздуха, 2-проволока для захвата образца, 3-корзина для влажного хлопка, 4противовес, 5-игольчатый клапан, 6-труба для выпуска отработанного горячего воздуха.

Устройство работает в следующем порядке: горячий воздух поступает в верхнюю часть камеры через воздуховод 1 и выходит из рабочей камеры с помощью вентилируемого горячего воздуховода 6, отдавая тепло поверхности образца перед выходом в атмосферу. Измерение расхода горячего воздуха измеряется и контролируется с помощью анемометра АМ-50, который имеет диапазон измерения от 0,1 до 15 м/с и измеряет с точностью до $0,03 \mathrm{~m} / \mathrm{c}$. Определим изменение температуры горячего воздуха в процессе исследования в пределах $50^{\circ} \mathrm{C}, 60^{\circ} \mathrm{C}, 70^{\circ} \mathrm{C}$. Дополнительные исследования были проведены на вновь созданном лабораторном оборудовании с целью изучения влияния плотности хлопкового сырья на процесс разделения влаги (рисунок 2). Здесь важно определить, какой плотностью ограничивается степень извлечения влаги из хлопкового сырья. В образцах было обнаружено, что влажность хлопка приближается к равновесию в результате процесса диффузии [6]. Уравнение протекания диффузионного процесса в хлопковом сырье можно записать в виде трехмерного уравнения в следующем виде.

$$
\frac{\partial c}{d \theta}=k \frac{\partial^{2} c}{\partial x^{2}}+\frac{\partial^{2} c}{\partial y^{2}} \frac{\partial^{2} c}{\partial z^{2}}
$$

здесь,

с- концентрация водяного пара;

$\theta$ - время; 
k- коэффициент диффузии;

$x, y$ и $z$-в декартовой системе координат.

Перед тем как проводить опыты, определяем график ползунков и шкалу измерений, определяющую количество выделений влаги в процентах.

\section{3. Результаты эксперимента и их обсуждение}

Проведенные исследования будут полезны в качестве основы для разработки нового оборудования для сушки и смешивания хлопкового сырья. Здесь важно знать плотность хлопчатобумажного сырья и скорость действия сушильного агента и влияние температуры на скорость потери влаги. Полученные результаты были проанализированы для получения одной экспоненциальной функции с использованием математического программирования с учетом весовых коэффициентов. Используя уравнение и проанализировав несколько существующих моделей, выберем модифицированный вариант функции.

$$
D=T^{A}\left[c+\delta\left(1-e^{b v}\right)\left(e^{-k \rho}\right)\right]
$$

здесь;

T-температура, ${ }^{0} \mathrm{C}$;

v-относительная скорость;

$\rho$-плотность;

$A$ - коэффициент регрессии.

Значение D-коэффициента найдено для прямоугольной и сферической среды с помощью программы SYSNLIN. Результат приведен в таблице 1.

Таблица 1. Значение коэффициента найденное с помощью программы SYSNLIN.

\begin{tabular}{llllllllc}
\hline $\begin{array}{l}\text { Тип } \\
\text { воздуха }\end{array}$ & $\mathrm{F}$ & $\mathrm{A}$ & $\mathrm{C}$ & \multicolumn{1}{c}{$\delta$} & $\mathrm{b}$ & $\mathrm{k}$ & 2 & Ошибка \\
\hline Влажный & 1 & $1.32419 \pm 0$. & $0.010376 \pm$ & $0.402224 \pm$ & $0.02666 \pm 0$. & $166.3958 \pm$ & \multirow{2}{*}{0.90} & \multirow{2}{*}{1.41} \\
& 2 & 128 & 0.0059 & 0.0515 & 037 & 33.3 & & \\
Сухой & 2 & $1.74778 \pm 0$. & $0.006325 \pm$ & $0.078257 \pm$ & $0.079966 \pm$ & $150.5391 \pm$ & 0.96 & 9.45 \\
& 3 & 0997 & 0.0029 & 0.0344 & 0,0172 & 18.55 & & \\
Влажный & 1 & $1.327424 \pm$ & $0.009180 \pm$ & $0.359981 \pm$ & $0.024216 \pm$ & $167.2370 \pm$ & 0.90 & 1.03 \\
& 2 & 0.128 & 0.0047 & 0.498 & 0.0366 & 32.95 & & \\
Сухой & 2 & $1.819824 \pm$ & $0.004953 \pm$ & $0.062126 \pm$ & $0.079775 \pm$ & $149.0450 \pm$ & 0.90 & 7.33 \\
& 3 & 0.103 & 0.0023 & 0.0278 & 0.0172 & 18.45 & & \\
\hline
\end{tabular}



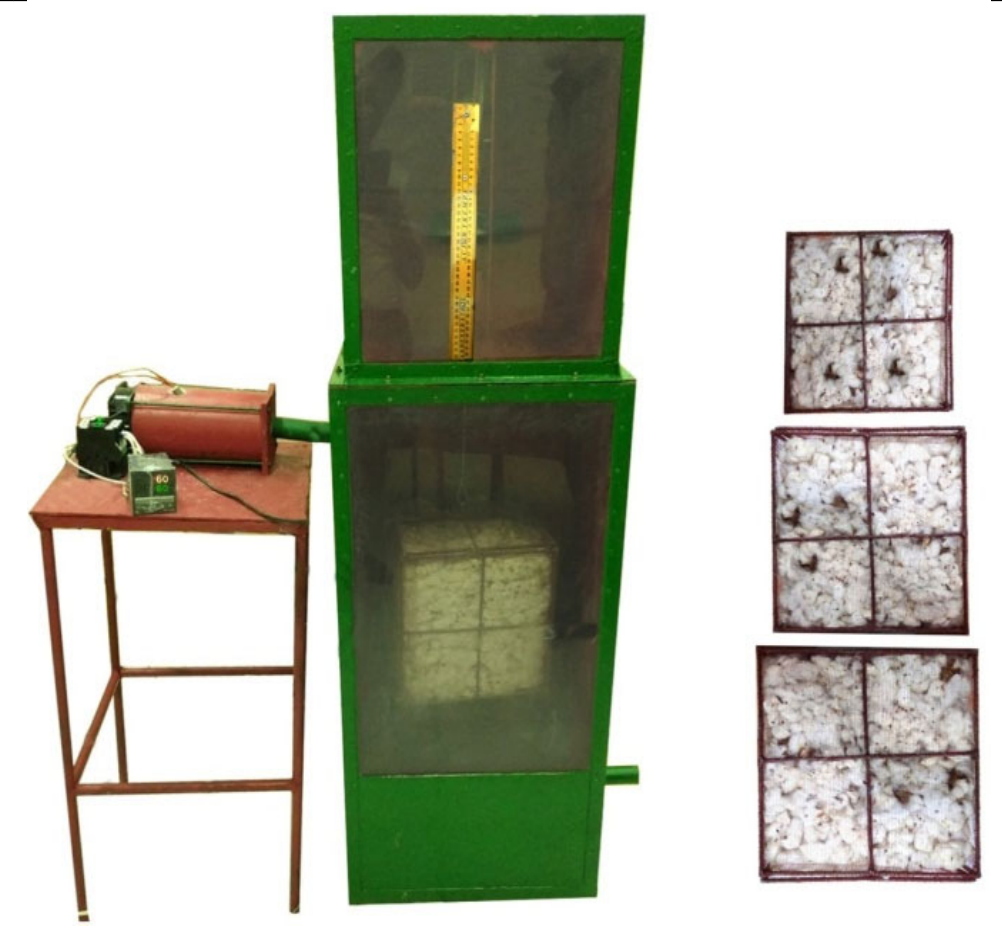

Рисунок 2. Обзор лабораторного прибора.

Следует отметить, что при решении вышеназванной задачи влияние плотности и температуры на скорость разделения влаги можно определять в следующем порядке, введя их в качестве переменных [7]. Температуру горячего воздушного потока, воздействующего на хлопчатобумажное сырье, выбирали $50^{\circ} \mathrm{C}, 60^{\circ} \mathrm{C}, 70^{\circ} \mathrm{C}$. Принимая скорость движения воздуха (осушающего агента) за 0,2 м/с, 0,4 м/с и 0,6 м/с, пробы отбирали в диапазоне плотности 0,5-

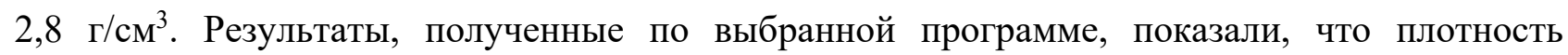
хлопкового сырья, скорость высыхания агента и температура горячего воздушного агента оказывают значительное влияние на процесс отделения влаги от хлопкового сырья в этом ограниченном диапазоне.

Влияние относительной скорости сушильного агента и плотности хлопкового сырья на потерю влаги и скорость десорбции (сушки) при заданной температуре было изучено с использованием системы HVI. Для экспериментов были отобраны образцы из разных сортов. Для контроля температуры воздуха использовались датчики температуры SIM-12 H с точностью $\pm 0,2{ }^{\circ} \mathrm{C}$, помещенные на образец. По результатам проведенных исследований получена зависимость влияния относительной скорости теплового агента на количество влагоотбора (рисунок 3). 


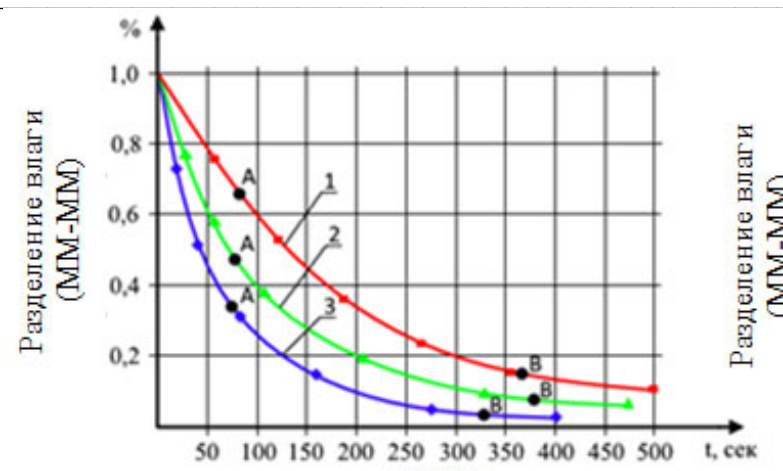

$\mathrm{t}=50^{\circ} \mathrm{C}$

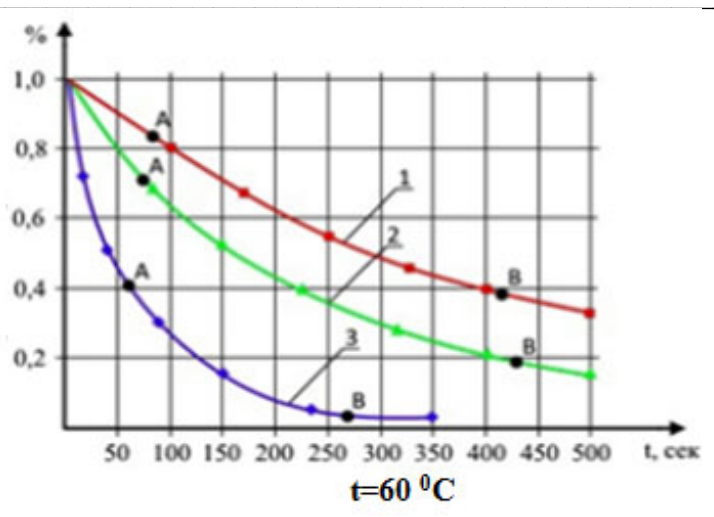

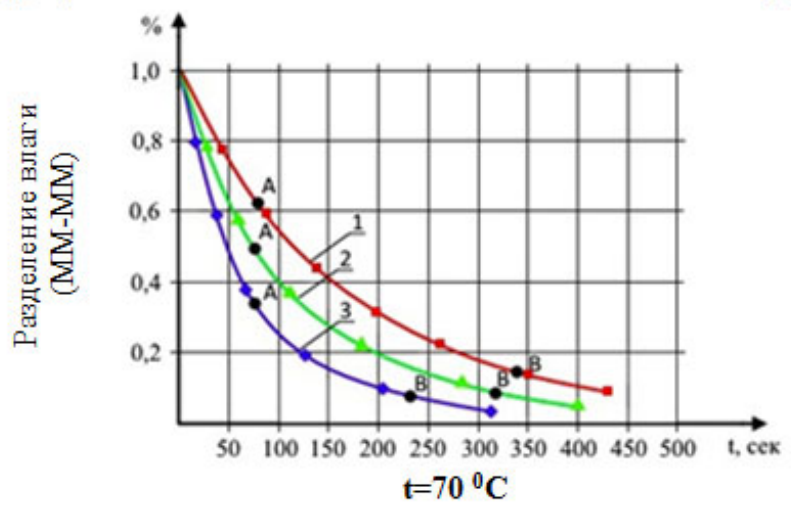

Рисунок 3. График зависимости изменения количества влаги в хлопке-сырце от скорости горячего воздуха и его температуры по вариантам.

$$
W=14 \%, \quad 1-V=0,2 \mathrm{~m} / \mathrm{c}, \quad 2-V=0,4 \mathrm{~m} / \mathrm{c}, \quad 3-V=0,6 \mathrm{~m} / \mathrm{c}, \quad \rho=0,52 / \mathrm{cm}^{3},
$$

Из анализа полученных зависимостей следует:

- Первоначально скорость процесса отделения влаги постоянна и может наблюдаться в виде прямой линии, а затем изогнутой линии, т.е. в начале процесса сушки происходит диффузия в поверхностных слоях хлопка-сырца, скорость процесса меньше зависит от скорости сушильного агента и является постоянной величиной.

Первая критическая точка А показывает период окончания постоянной скорости, при этом из графика видно, что после 75 секунд количество влаги снижается до 12,8 \%. Следовательно, из графика можно увидеть, что существуют особые (одиночные или особые) точки А и В, указывающие на внешние и внутренние зоны диффузии во время периода отделения влаги.

Таким образом, результаты показали, что изменение относительной скорости осушающего агента от 0,2 до 0,6 м/с оказывает значительное влияние на скорость выделения влаги, как ожидается, при различных температурах осушающего агента. Увеличение относительной скорости высыхающего агента привело к увеличению скорости передачи влаги. В ходе лабораторных анализов не наблюдалось видимых структурных изменений в хлопчатобумажном сырье и его волокнах, подвергавшихся воздействию горячего воздуха. 


\section{4. Заключение}

Учитывая эффективность и энергоэффективность предлагаемого лабораторного устройства, мы можем сделать заключение о том, что получены закономерности изменения влажности хлопкового сырья при различных значениях скорости теплого воздуха. Изучено влияние плотности хлопчатобумажного сырья и относительной скорости движения воздуха на изменение коэффициента влагоотдачи при различных температурах воздушного потока и установлено, что при значении плотности 0,5 г $/ \mathrm{cm}^{3}$ процесс влагоотдачи в хлопчатобумажном сырье выше.

\section{Список литературы}

[1] Gary, L. Relative Velocity, Density, and Temperature Effects on Cotton Moisture Transfer Rates / L. Gary, J. Barker, L. Weldon, G. Mathew, G. Pelletier, A. Holt // The Journal of Cotton Science. 2001. - № 5. - P. 243-251.

[2] Rakhmonov, Kh. Relative speed and temperature effect investigation of the of the drying agent on the moisture content of cotton / Kh. Rakhmonov, S. Fayziev, Kh. Rakhimov, D. Kazakova // E3S Web of Conferences. - 2021. - № 264, 04008. - P. 1-7.

[3] Fayziyev, S. Kh. Study of effect of speed and temperature of the drying agent in the feeder-loosened of new design on the quality of fiber / S.Kh. Fayziyev, Kh.K. Rakhmonov // International journal of emerging trends in engineering research. $-2020 .-8(10)$. - P. 7008-7013.

[4] Abrorov, Akbar. Ibodullo Sohibov and Matluba Quvoncheva Vacuum Installation of Technology of Deep Ion-Plasmic Nitriding Disc Saw Of Fiber Separating Machines / Akbar Abrorov, Shukhrat Salimov // International journal of emerging trends in engineering research. - 2020. 7(1). - P. 12406-12409.

[5] Rakhmonov, Kh.K. The analysis of dynamics of the machine unit with the mechanism of the screw conveyor of the distributor of raw cotton. "Science and practice: a new level of integration in the modern world" / Kh.K. Rakhmonov // Conference Proceyedings. B\&M Publishing. USA, San Francisco, California. - 2018. - P. 45-49

[6] Majidov, A.T. / A.T. Majidov, N.M. Safarov //International Journal of Engineering and Advanced Technology. - 2020. - № 9(3). - P. 3812-3816.

[7] Fayziyev, S.Kh. Improvement of equipment and technology of drying of the cotton mass and its technological assessment on the basis of its thermal properties / S.Kh. Fayziyev, Kh.Q. Rakhmonov // International journal of advanced research in science, engineering and technology. - 2019. - № 6(5). - P. 9496-9500. 